\title{
Analysis of Green Packaging Materials and Packaging Emotion
}

\author{
Bing Liu 1, a, Ruiqiu Pang 2, b,* \\ ${ }^{1}$ Academy of Fine Arts, Northeast Normal University, Changchun130024, China \\ ${ }^{2}$ School of Geographical Sciences, Northeast Normal University, Changchun130024, China \\ aice8515@163.com, bfuliu6286@163.com
}

Keywords: Green Packaging, Packaging Materials, Packaging Emotion.

\begin{abstract}
This paper begins with the understanding of the concept of green packaging design, analyzes the principle on the selection of packaging materials, studies the packaging emotion contained in the material, and discusses the important position and function of green packaging materials in packaging design. Packaging design must take full account of emotional factors, so as to realize the new and unique packaging design and the perfect fit of environmental protection; in the packaging design of modern goods, the introduction of green design concept is the inevitable development of modern society, the packaging designer should understand the internal and external characteristics of green packaging materials, advocate green packaging culture and packaging emotion.
\end{abstract}

\section{Introduction}

Packaging is an important part of commodity production and circulation, with the continuous progress of modern material civilization and the continuous development of science and technology, the packaging waste left after the use of the Commodity, to the ecological environment has brought tremendous pressure. At present, the world has set off a wave of "green packaging design, environmental protection, resource conservation", it is a new design concept, effectively solve packaging and environmental issues, and control the packaging waste and "white pollution" [1-4].

Excellent green packaging is mainly reflected in the selection of packaging materials, and in the use of materials recycling and waste disposal and other aspects, effectively protect the environment and save resources, so as to achieve the perfect combination of environmental protection and economic benefits [5-7].

\section{Principle Analysis of Packaging Material Selection}

The concept of green packaging design is to protect the environment at the same time, to ensure the maximization of economic benefits. In terms of environmental protection, the packaging material is required to have the function of degradable recycling, so as to realize the sustainable development of human society, the combination of economic and environmental value, is the core of green design.

\subsection{Selection of Packaging Materials: Return to the Traditional, Choose to Use Back to the Natural Material.}

Material is the basis of building packaging. Packaging design process is based on material, around the material, to play the designer thought and wisdom, so as to form the work of creation, so it can be said, packaging art is a kind of material art. Designers according to the shape of the material, color, texture, to play a certain association, to create a certain artistic conception, to design a combination of material and spirit of the packaging works. China is one of the four ancient civilizations in the world, have a long history, accumulated a lot of excellent national packaging classic works, these packaging and packaging materials to maintain a high degree of consistency and unity, this consistency and unity, is a specific embodiment of the packaging to achieve a certain degree of height. Such as the use of natural wood, bamboo, rattan, clay, leather, or even the stem or leaf of plant, to produce a variety of packaging products, suit one's measures to local conditions, these packaging materials are natural 
weathering decomposition, and can return to the natural green raw materials, after a simple processing, and elaborate decoration, fully embodies the traditional commodity and the characteristics of the packaging of the nation, these green materials are naturally free of pollution, can be repeated use, these simple packaging practices, in line with the concept of modern green packaging.

Pure natural, non-decorative decoration is the traditional Chinese packaging design style; this is the concept of Chinese traditional packaging design, and the essence of Chinese traditional art.

\subsection{Selection of Packaging Materials: Low Energy Consumption, Low Cost and Less Pollution.}

Green packaging material is the basis of green packaging design, green packaging materials should be selected with low energy consumption, low cost and less pollution, at the same time, the material should be easy to process, in the process of packaging products, no pollution or less pollution. Therefore, the selection of green materials should be considered from the following aspects.

A. The implementation of packaging reduction. Optimize the structure of packaging, To reduce the volume and the number of packages; optimization design of packaging structure, the implementation of thin wall technology, containerization, break up the whole into parts, in order to meet the protection, convenience, sales and other functions, to minimize the use of packaging materials.

B. Re-use of packaging supplies. Cans, bottles and other packaging after recovery, can be used again, for example, glass beer bottle, Beer bottles are different from plastic bottles or disposable-packaging products, can be repeated use many years.

C. Recovery and reuse of packaging materials. After the completion of the use of packaging materials, after proper treatment, can be reused, incineration and utilization of heat energy, compost improved soil, this not only saves raw materials for packaging, also can promote the recycling of resources.

D. The degradability of the material. Biodegradable material is a kind of material, which is worthy of further research and development, after the use of the material, under the action of light and action, or by microorganisms in soil and water, decomposition and reduction in the natural environment, in the form of non-toxic to re-enter the ecological environment, return to nature.

E. Packaging materials for human and biological non-toxic and harmless. Packaging materials should not contain toxic elements, bacteria, heavy metals, etc. Packaging products, from raw material acquisition, materials processing, manufacturing products, product use, waste recycling, until the final treatment of the whole process, should all not be harmful to the human body and the environment.

Green packaging is the most thrilling revolution of twenty-first Century, is the fundamental needs of industrial development. As a designer should advocate green packaging design, establish the concept of green environmental protection design, choose non-toxic harmless, easy to decompose materials, the whole process of design to achieve green, ecological, human, and the combination of material and spirit, to contribute to the natural environment and sustainable development.

\section{Analysis of Packaging Emotion in Material}

Different packaging materials show different visual features, the packaging of the emotion, which is formed through the packaging material, pattern, color and shape to create a unique style and art, to give consumers a different emotional enjoyment, and win their goodwill and psychological identity. Emotional expression of packaging is the inevitable trend of social development.

\subsection{The Aesthetic Expression of Materials in Packaging Design}

The artistic appeal of packaging design, through the color, shape, light and other materials, the nature of the essence, to convey to our visual experience. Different materials often give people different feelings, this is because the materials have their own texture, structure and organization, will give people different visual and tactile, material's size, weight, soft, warm and cold will make people have a wealth of aesthetic consciousness and spiritual resonance.

Different materials have different cultural backgrounds, And these materials, reveal the cultural background is moved by sight unconsciously reveals the nature, circumstances and social circumstances, so as to enable consumers to achieve spiritual satisfaction. Packaging designers should 
be based on the characteristics of the material itself, to give packaging to appeal and vitality, the use of "material language" to convey commodity information, to bring consumers the feeling of beauty.

\subsection{Sustainable Development of Packaging Materials.}

Green packaging is harmless to human health and ecological environment, it is characterized by recycling, and this is closely related to the sustainable development strategy. Product packaging in accordance with the requirements of the protection of the ecological environment, Through the selection of raw materials, use and recycling of a series of processes, to achieve the purpose of energy saving, reduction, reduce waste of resources, easy recovery, renewable, biodegradable.

Rational use of environmentally friendly materials, correct understandings of the role of packaging design in social life. In the design, the fabrication process and encapsulation technique have been further improved and perfected, to focus on the design of human culture and contracted design ideas to design and thinking. Use more eco-friendly materials, let consumers know that the goods and packaging are healthy and safe; a transparent form of packaging conveys the quality of the goods, to allow consumers to see the real goods, these are directly reflected the important role of excellent packaging design. A one-sided understanding of human nature, false and exaggerated packaging, the use of toxic and harmful packaging materials, will be turned into the pursuit of profit phenomenon, these are to meet the short-term interests of a small number of people, while sacrificing the long-term interests of mankind. Focus on green consumer psychology; designers should have a keen insight, in order to take a long-term responsibility for the society, with the emphasis on environmental protection, Harmonize with nature, find out the design elements for the new era, to design a package with vitality. Green packaging can reduce resource crisis and reduce pollution.

In today's increasingly competitive market environment, packing design has become a core competence. The consumer demand for goods packaging not only has a variety of functions, easy to carry, but also in the design of more humane care. Through the development and mining of packaging function, in the increasingly perfect products into the humanized design elements, make people feel warm and blessedly familiar. Material is the carrier of humanized design; we should break through the traditional packaging materials, the pursuit of more healthy green packaging material, in order to fully reflect the characteristics of humanized concept, to reduce the pollution and reduce the harm to the environment.

\section{Summary}

The use of material is a kind of design language, in packaging design different materials give people different visual and tactile effects. Most of the green packaging materials have their own characteristics, the application of material should convey aesthetic pursuit, and it is necessary to explore the relationship between different packaging materials and emotional appeal. As a designer to analyze and summarize each kind of green packaging materials, to fully grasp its internal and external characteristics, to have an innovative combination of materials, the formation of a variety of emotional packaging to meet people's needs.

With the development of economy and trade reformation in world, protection of resources and environment, to create a good space for survival and development, it is the basic strategy for the sustainable development of global economy. Based on human perception, the material is evaluated and analyzed, to explore the tactile language of packaging materials, rational use of packaging material elements, to communicate with consumers in the senses and spirit, in order to achieve the purpose of promoting consumption, it has important practical significance for the rational circulation of products. Green is expected to be the most charming color of twenty-first Century; green packaging expected to be the future of packaging design. 


\section{Acknowledgments}

The authors gratefully thanks the financial support by Research Project in Jilin Social Science Fund Project (2013BS14); Youth fund of Northeast Normal University in philosophy and social science school projects-art project (MSZX2012-01).

\section{References}

[1]. Justine A Spack, Virginia E Board, Lindsay M. Crighton, et al. It's Easy Being Green: The Effects of Argument and Imagery on Consumer Responses to Green Product Packaging. Environmental Communication. Vol. 6 (2012) No. 4, p. 441-458.

[2]. Sara González-García, Esther Sanye-Mengual, Pere Llorach-Masana, et al. Sustainable Design of Packaging Materials. Part of the series Environmental Footprints and Eco-design of Products and Processes. Vol. 11 (2016), p. 23-46.

[3]. Y Li, DY Yang, WJ Gu. The Networked City and the Sustainable Packaging Design. Applied Mechanics \& Materials. Vol. 178-181 (2012), p. 1079-1082.

[4]. K Marsh, B Bugusu. Food packaging-roles, materials, and environmental issues. Journal of Food Science. Vol. 72 (2007) No. 3, p. 39-55.

[5]. S Ross, D Evans. The environmental effect of reusing and recycling a plastic-based packaging system. Journal of Cleaner Production. Vol.11 (2003) No. 5, p. 561-571.

[6]. D Huang. Green packaging, design goes first. Packaging Engineering. Vol.26 (2005) No. 6, p.214-216. (In Chinese)

[7]. CP Lin. Study of Green Packaging Based on Design for Environment. Light Industry Machinery. Vol.30 (2006) No. 10, p.199-228. (In Chinese)

\section{Corresponding Author}

Ruiqiu Pang, Associate Professor, Northeast Normal University, CHINA, fuliu6286@163.com. 